\title{
Obesity Etiology: Examination of Fast-Food Eating among College Students
}

\author{
Susan Stockton ${ }^{1 *}$ and David Mc.A Baker ${ }^{2}$ \\ ${ }^{1}$ Department of Nutrition and Kinesiology University of Central Missouri Warrensburg, MO, USA
}

${ }^{2}$ Tourism \& Hospitality Management, University of Central Missouri, Warrensburg, USA

\section{Abstract}

Objectives: Discussing the etiological constituents of obesity and exploring fast food (FF) consumption among college students are the purpose of this study.

Methods: Electronic surveys were distributed the spring semester 2012. Respondents data were analyzed for mean, standard deviation and frequency distribution based on age groupings.

Results: Survey responses indicated that younger aged college students in this study consumed more fast food than has previously been reported and all ages present contradictory eating behavior with food knowledge. Students admit to eating fast food at least once per week or more.

Conclusion: Analysis of the research data yields continuing concern for health educators to address not only the frequency of fast food consumed but also perceptions of type of food eaten correlating with feelings of energy/ health promotion or accelerated age-related changes.

Keywords: Negative health outcomes; Obesity; Fast food; Health; Perception; Aging

\section{Introduction}

According to Proceedings from the National Academy of Sciences USA, over one billion persons are overweight and 300 million are obese worldwide [1]. David Satcher, MD, PhD, $16^{\text {th }}$ Surgeon General of the United States, reveals there were 61 percent of American adults overweight or obese and almost 12 percent of children in 2001 [2]. Today, more than two-thirds of adults and nearly one third of children and teens are overweight or obese [2]. Ten years ago there was not one state with an obesity figure above 24 percent, now 43 states have higher obesity rates than the highest state of 2000, and obesity rates exceed 25 percent in 38 states [2] According to Healthy People 2020, adults, children and adolescents who are obese or are considered obese comprise two determinants of the 26 Leading Health Indicators (LHI) [3]. Leading Health Indicators (LHI) are issues that represent significant threats to the public's health and are designed to address factors that promote quality of life, healthy behaviors, and healthy development across all stages of life [3]. For each of the LHIs it can be proposed that obesity affects multiple ages, is multi-factorial, and is a significant public health threat [4]. Caring for the health of her citizens, the US government recognized a need to assist the public with their food selection habits. First published in 1894 was a small booklet on dietary recommendations [5]. Overtime these recommendations have been updated and changed culminating in the annual review and publication of the food guide pyramid since 1992. Some critics of the food pyramid recommend changing the proportions of food types and include exercise and weight management as the base [6] while others place water as the base and include the schedule of when to eat specific food types, i.e., lean meat, fish and sea food weekly, not daily [7]. One of the arguments about the difficulty with following the food guide pyramid was the constantly changing status of what was considered a healthy diet, what to eat, how much to eat, and how frequently to eat. This dilemma persists today. US dietary recommendations as published online compared overweight, obese, and extreme obesity data from 1960-2008 revealing steady to a slight dip in overweight while obese figures increased $128 \%$ and extreme obesity escalated $329 \%$ [8].
Sampey et al. found significant differences in male Wistar rats fed a cafeteria diet, similar to that consumed by humans, when compared with a traditional lard-based high-fat diet [9]. The rats fed the cafeteria diet displayed inflammation in white fat, brown fat, and liver, along with exaggerated obesity, glucose intolerance and hepatosteatosis. Hepatosteatosis, a more benign form of hepatocyte dysplastic changes, then steatohepatitis, which ultimately leads to fibrosis and cirrhosis, are both present within the diagnosis of Nonalcoholic fatty liver disease (NAFLD) [9]. Nonalcoholic steatohepatitis (NASH) not only leads to liver cell insulin resistance but also diminishes gluconeogenesis allowing accumulation of fatty infiltrates and precipitates the serious changes (fibrosis and cirrhosis) noted previously. NAFLD is strongly associated with visceral adiposity [9] and visceral adiposity is considered to be the more hazardous body fat $[4,9,10]$. NAFLD can be induced in mice by a three week methionine and choline deficient diet [11]. It is well established that a diet lacking sufficient $B$ vitamins results in altered methionine pathways and the production of homocysteine, an inflammatory marker, and that choline and inositol are required for phase two liver detoxification [12,13]. All refined carbohydrates contain less nutrients than their unrefined counterparts, especially in terms of B vitamins, antioxidants, trace minerals, flavonoids, and fiber $[4,14]$. Recent discoveries have found that methyl forming foods such as onions, beets, garlic, strawberries, citrus, and dark green leafy vegetables can alter inheritance-the epigenetic influence which controls gene expression [15]. These foods are not typical selections from fast food eating establishments.

${ }^{*}$ Corresponding author: Susan Stockton, North Morrow 111, Department of Nutrition and Kinesiology, University of Central Missouri Warrensburg, MO 64093, USA, Tel: (660) 543-8893; E-mail: sstockton@ucmo.edu

Received October 18, 2013; Accepted November 25, 2013; Published November 29, 2013

Citation: Stockton S, Baker DMA (2013) Obesity Etiology: Examination of FastFood Eating among College Students. Aging Sci 2: 114. doi: 10.4172/23298847.1000114

Copyright: (c) 2013 Stockton S, et al. This is an open-access article distributed under the terms of the Creative Commons Attribution License, which permits unrestricted use, distribution, and reproduction in any medium, provided the original author and source are credited. 
A possible contributing factor to becoming overweight/obese is over consumption of refined grains [12]. Most grain products available from fast food establishments are refined and may lead to hyperphagia of up to $40 \%$ of total caloric intake which also affects the auto-regulatory mechanism for energy balance [16]. In response to increased refined carbohydrate consumption (hyperglycemia) the triglyceride lipid fraction is increased [13]. Increased metabolic activity in the liver to assist with lowering hyperglycemia yields accelerated manufacture of triglycerides and abdominal adiposity [13] (Figure 1).

Adipose tissue as an endocrine organ increases proinflammatory cytokines, free fatty acids, TNFa, IL6, IL8 [11] compounding the triglyceride/cytokine hepatic insult and leads to hepatic lipid peroxidation, inflammation, hepatosteatosis, possible diagnosis of NAFLD, impaired insulin signaling, insulin and other hormonal imbalances (leptin, ghrelin, resistin), NASH diagnosis, and impaired lung function in elderly men and women $[4,17,18]$. NASH diagnosis is confirmed by a combination of intact and cleaved cytokeratin 18 (CK-18), serum adiponectin and serum resistin $[12,13,19,20]$. There is debate about a causal relationship between hepatic triglyceride content and insulin resistance based on the apolipoprotein C3variants [21,22]. Examination of digested food from elderly individuals in residential care centers versus independent living structures reveals altered micro biota between groups. Those with less variety in their diets had altered microbiota and this alteration was associated with chronic health conditions, obesity, inflammatory diseases, and accelerated aging [23]. Contradictory findings reveal something of the complexity of weight maintenance, health and aging. Partridge (2012) states that both benefit and harm were the result of caloric restriction among older adults and feels that the dichotomous conclusion may be due to the composition of food eaten and food quantity [23]. Power and Almeida (2012) found another paradox with obesity in later life such that mortality was highest in older people whose body mass index (BMI) decreased over time while those with increasing BMI had brain shrinkage [24].

Other literature examining the proportion of fat, carbohydrate, and protein in the diet has found that low carbohydrate was more beneficial for weight loss and did not adversely affect the lipid fractions on a standard metabolic blood profile [16,25-31]. While recent studies are examining the role of a high fat diet as a contributing factor for bacterial endotoxins (lipopolysaccharides) which trigger toll-like receptors preparatory to inflammation and inflammation is the key driver for chronic disease of which Type 2 Diabetes Mellitus (T2DM) and obesity are foremost [28-31]. Marcos et al. state that there are numerous pathological situations where nutrients (fat, carbohydrate, protein, vitamins, minerals) play a primary or secondary determinant role for some underlying immunological impairment of which obesity is now subsumed [32]. Interesting findings concerning water consumption may also contribute to the US obesity epidemic and etiological data. Thirty-seven percent of Americans have a thirst mechanism that is misinterpreted as hunger or a need for food. Mild dehydration is known to impede metabolic activity by three percent.

Haines, O'Neil, and Zanovec found that among college students FFI was $84 \%$ with $54 \%$ consuming at least once per week. Although students admitted that healthier food choices would be more costly and would pay more for the healthier options, if given the choice they would not eat the healthier food options [33]. The current study examines survey responses to FFI based on age groupings to see if differences on perception of food quality influences perceived levels of energy, FFI frequency, and FF items selected most frequently, degree of physical activity, and on a diet to lose weight exist. Currently enrolled college students' perception of healthy eating is examined in this research to determine criteria about fast food in relation to feelings of energy obtained from food, satisfaction with degree of physical activity, on a diet to lose weight, how often $\mathrm{FF}$ is consumed and what items are most frequently consumed for comparison between those aged 18-24, 25-30, 31-50, and over 50.

\section{Methods}

An Internet-based survey was distributed to investigate the relationship between FFI and the demographic data of age by college students in the mid-west. Internet surveys were used to increase the likelihood of participation due to college students' familiarity and accessibility with computer technology [4]. Internet surveys also provide for less cost, less preparation time for duplication and distribution, ease of collection and data entry for statistical analysis [34]. Fewer item completion errors, greater convenience for researcher and participant, more rapid and higher rate of return and less chance for social bias issues are other benefits associated with web surveys [34]. The survey was modified from the National Health and Nutrition Examination Survey (NHANES) [35]. Evaluating food selection and FF frequency among the different age's groups to determine the impact toward developing obesity was the focus of the revised survey (Appendix A).

Participants invited to complete the survey consisted of college students enrolled in both four-year and community college educational entities. According to institutional research statistics there were a total of 11,637 students attending the four year college during this research. Approximately 5,710 students were invited to participate from area community colleges. Response rate from the community colleges was $2.48 \%$. Total survey response rate was $2.65 \%$ or 543 total submitted surveys. This survey did not separate students by rank. Also, there was no control in place to prevent multiple survey submission by the same subject. Students over the age of 50 constitutes between 1-1 $1 / 2$ percent of the university population. Survey response rate from this group was three percent.

\section{Participant Recruitment}

Students were recruited for participation in the survey via announcements from respective student portal web pages. Also, instructors were sent an e-mail request to announce this research in their classes, an announcement was posted on Blackboard (an electronic instructional and communication medium), and an offer of extra credit for participating, provided the practice of extra credit was a typical component of their class pedagogy. With all requests the Uniform Resource Locator (URL) for the survey was included.

Once students received the URL they were directed to the informed consent documents and given instructions on how to complete and submit the survey. All components of this research were approved by the Human Subjects Research committee and Institutional Review Board prior to dissemination and request for participating.

\section{Survey Instrumentation}

This study used a brief 26-item Internet-based survey that included demographic questions, questions about subjects FFI frequency and type of fast food selection. This survey instrument 

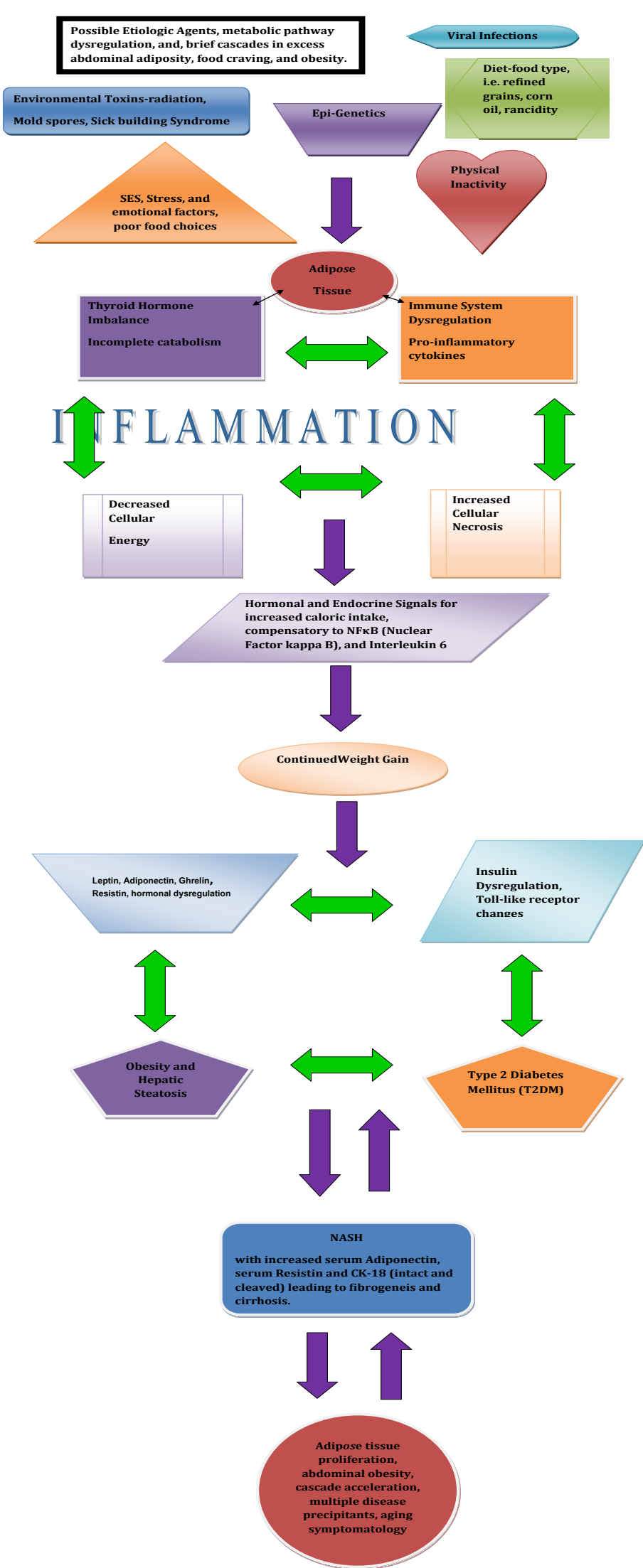

Figure 1: Examines the possible etiologic agents, metabolic pathway dysregulation, and, brief cascades in excess abdominal adiposity, food craving, and obesity. 
included questions relating food to feelings of energy and asked about the perceived degree of physical activity. Some questions were based on a five-point Likert-type scale ranging from never to always. This instrument has not undergone reliability and validity testing and was created as an exploratory, cross-sectional design instrument for correlation between fast food frequency, age, and perceived impact of FFI with this population. The Internet-based survey was developed using SurveyMonkey ${ }^{\circledR}$ [36] which is a fully web-based survey application that offers production and publication of surveys on the Internet through email messaging of URLs or posting on individual or corporate web sites. The survey was made available for approximately two weeks near the beginning of the spring semester 2012.

Descriptive statistics obtained included frequency, percent, and split file with age as the comparison variable. Skew and Kurtosis failed to reveal an abnormal distribution when examined using SPSS v. 19.1 .

\section{Results}

Table 1 contains select demographics, numbers, percent, means, and standard deviations as analyzed by SPSS $\mathrm{v}$ 19.1. Means and Standard Deviation of College Student Fast Food Intake (FFI) N=499

Younger aged individuals tended to feel more satisfied with their level of physical activity $(\mathrm{N}=172,47.4 \%)$ and to not be on a diet to lose weight $(\mathrm{N}=257,70.8 \%)$. An almost exact match between those 18-24 and those 31-50 years old and those 25-30 with those over 50 years of age on responses to quality of food consumed relating to feelings of increased energy ( $\mathrm{N}=454,>90.0 \%)$. Findings concerning the number of FF visits per week were supportive of other reports among college aged students in that $87.3 \%(\mathrm{~N}=317)$ stated they consumed $\mathrm{FF}$ and $68.3 \%(\mathrm{~N}=248)$ eat $\mathrm{FF}$ at least once per week.

Study participants were not restricted to a single access to the survey and thus the total number of unique responses may not accurately capture this population sample. Clarification of a fast food restaurant as those providing food via a drive-through window was for ease of understanding and convenience for participants and researchers and does not capture FF type food consumed at other locations. There were more females than males in all age groups which may provide more specific information about women compared to men but under represent the male view. There were more subjects in the 18-24 age grouping which represents the typical age for college students and supports the average from which the sample was taken (Table 2). Also females outnumber males' at all educational entities but not in the same proportion as were found with this sample.

\section{Discussion}

Statistics from this study reveal approximately $87 \%$ of respondents consume $\mathrm{FF}$ with $68 \%$ consuming at least one or more times per week. According to the CARDIA study those who consume FF two or more times per week averaged 10 pounds of increased weight [37]. Older aged individuals may feel that diet soda may be contributing to weight loss goals (reduction/maintenance) as all groups older than 18-24 had higher consumption of diet soda and reported being on a diet to lose weight. The literature suggests that diet soda actually contributes to weight gain and over consumption of carbohydrates [38]. Authorities are beginning to stress the importance of healthy fats and that saturated fat may actually lower the risk of heart disease, strengthen the immune, skeletal, and nervous systems as well as be vital for all healthy cells [39-41]. Other factors, with consumption of refined grains in particular, are the imbalances caused to minerals, specifically the loss of zinc with excess refined grain (wheat) and soy intake. As zinc is a metalloenzyme involved in several metabolic processes crucial for optimal immune system function, loss of zinc homeostasis and disruption of gut flora microbiota may prove problematic for a properly functioning immune system presenting a synergistic cascade toward the etiology of obesity, chronic disease, age-related health deficits. To determine more specific health risks with FF consumption, especially among those enrolled in institutions of higher learning where one might expect healthy and informed diet, exercise, and lifestyle habits, a 30-day diet diary, health history, waist-to-hip ratio, and lifestyle epidemiological data could further elucidate the factors predisposing to FFI and the connection to causative factors of obesity. This study finds an increase in those consuming fast food once or more times per week (87.3\%) compared to previous research among this population but that college students also consume less regular soda than anticipated [42]. Consistent with other research students' perception and behavior may be in disharmony with regard to FF selection, FF eating frequency, and their beliefs about quality of energy/health. With $70 \%$ mortality and $75 \%$ of the health care budget in the US related to chronic disease, a corollary pre-disposition to develop obesity, discovering the etiological dynamics associated with our food consumption, and contingent negative health outcomes when positive food selection practices are ignored, is paramount [43]. Further research into the motivations for food selection, understanding biochemical and physiological cascades from both positive and negative food selection- such as, refined grains, soda, and artificial sweeteners, substances that promote and maintain the intestinal ecosystem, as

\begin{tabular}{|l|c|c|}
\hline Table $\mathbf{1}$ & Mean & S.D. \\
\hline Variable (n=499) & Number & $\%$ \\
\hline Gender & $\mathbf{1 . 7 8}$ & $\mathbf{0 . 4 2}$ \\
\hline Male=1 & 110 & 22.00 \\
\hline Female=2 & 389 & 78.00 \\
\hline Age, range in years & $\mathbf{t 1 . 4 9}$ & $\mathbf{0 . 8 6}$ \\
\hline 18-24=1 & 363 & 72.70 \\
\hline $25-30=2$ & 45 & 9.00 \\
\hline $31-50=3$ & 76 & 15.20 \\
\hline Over 50=4 & 15 & 3.00 \\
\hline Food Quality and Type Influences feelings of energy $\mathbf{( n = 4 9 9 )}$ & $\mathbf{1 . 0 9}$ & $\mathbf{0 . 2 9}$ \\
\hline Yes=1 & 454 & 91.00 \\
\hline No=2 & 45 & 9.00 \\
\hline Visits to a FF restaurant in the past month & $\mathbf{1 . 1 0}$ & $\mathbf{0 . 7 0}$ \\
\hline None=0 & 69 & 13.80 \\
\hline 1-2 times per week=1 & 334 & 66.90 \\
\hline 3-4 times per week=2 & 77 & 15.40 \\
\hline 1 time per day=3 & 14 & 2.80 \\
\hline 2 or more times per day=3 & 5 & 1.00 \\
\hline Satisfaction with Physical Activity & $\mathbf{1 . 5 7}$ & $\mathbf{0 . 5 0}$ \\
\hline Yes=1 & 215 & 40.60 \\
\hline No=2 & 284 & 53.70 \\
\hline Currently on a Diet to Lose Weight & $\mathbf{1 . 6 9}$ & $\mathbf{0 . 4 6}$ \\
\hline Yes=1 & 154 & 29.10 \\
\hline No=2 & 345 & 65.20 \\
\hline
\end{tabular}

Table 1: Contains select demographics, numbers, percent, means, and standard deviations as analyzed by SPSS v 19.1. Means and Standard Deviation (in bold) of College Student Fast Food Intake (FFI) N=499. 
Citation: Stockton S, Baker DMA (2013) Obesity Etiology: Examination of Fast-Food Eating among College Students. Aging Sci 2: 114. doi: 10.4172/2329-8847.1000114

Page 5 of 6

\begin{tabular}{|c|c|c|c|c|c|c|c|c|}
\hline Age & \multicolumn{2}{|c|}{$\mathbf{1 8 - 2 4}$} & \multicolumn{2}{c|}{$\mathbf{2 5 - 3 0}$} & \multicolumn{2}{c|}{$\mathbf{3 1 - 5 0}$} & \multicolumn{2}{c|}{ Over 50 } \\
\hline & $\mathrm{n}=$ & $\%$ & $\mathrm{n}=$ & $\%$ & $\mathrm{n}=$ & $\%$ & $\mathrm{n}=$ & $\%$ \\
\hline Male & 79 & 21.8 & 11 & 24.4 & 14 & 18.4 & 6 & 40.0 \\
\hline Female & 284 & 78.2 & 34 & 75.6 & 62 & 81.6 & 9 & 60.0 \\
\hline Total & $\mathbf{3 6 3}$ & $\mathbf{1 0 0 . 0}$ & $\mathbf{4 5}$ & $\mathbf{1 0 0 . 0}$ & $\mathbf{7 6}$ & $\mathbf{1 0 0 . 0}$ & $\mathbf{1 5}$ & $\mathbf{1 0 0 . 0}$ \\
\hline
\end{tabular}

Fast food visits

\begin{tabular}{|c|c|c|c|c|c|c|c|c|}
\hline Age & \multicolumn{2}{|c|}{$\mathbf{1 8 - 2 4}$} & \multicolumn{2}{|c|}{$\mathbf{2 5 - 3 0}$} & \multicolumn{2}{c|}{$\mathbf{3 1 - 5 0}$} & \multicolumn{2}{c|}{ Over 50 } \\
\hline & $\mathrm{n}=$ & $\%$ & $\mathrm{n}=$ & $\%$ & $\mathrm{n}=$ & $\%$ & $\mathrm{n}=$ & $\%$ \\
\hline none & 46 & 12.7 & 7 & 15.6 & 15 & 19.7 & 1 & 6.7 \\
\hline 1_2perwk & 248 & 68.3 & 27 & 60.0 & 49 & 64.5 & 10 & 66.7 \\
\hline 3_4perwk & 52 & 14.3 & 9 & 20.0 & 12 & 15.8 & 4 & 26.7 \\
\hline 1perday & 12 & 3.3 & 2 & 4.4 & 0 & 0 & 0 & 0 \\
\hline 2perday & 5 & 1.4 & 0 & 0 & 0 & 0 & 0 & 0 \\
\hline Total & $\mathbf{3 6 3}$ & $\mathbf{1 0 0 . 0}$ & $\mathbf{4 5}$ & $\mathbf{1 0 0 . 0}$ & $\mathbf{7 6}$ & $\mathbf{1 0 0 . 0}$ & $\mathbf{1 5}$ & $\mathbf{1 0 0 . 0}$ \\
\hline
\end{tabular}

Diet Soda

\begin{tabular}{|c|c|c|c|c|c|c|c|c|}
\hline Age & \multicolumn{2}{|c|}{$\mathbf{1 8 - 2 4}$} & \multicolumn{2}{c|}{$\mathbf{2 5 - 3 0}$} & \multicolumn{2}{c|}{$\mathbf{3 1 - 5 0}$} & \multicolumn{2}{c|}{ Over 50 } \\
\hline & $\mathrm{n}=$ & $\%$ & $\mathrm{n}=$ & $\%$ & $\mathrm{n}=$ & $\%$ & $\mathrm{n}=$ & $\%$ \\
\hline NvrDrkDt & 271 & 74.7 & 34 & 75.6 & 48 & 63.2 & 5 & 33.3 \\
\hline Rarely & 25 & 6.9 & 2 & 4.4 & 6 & 7.9 & 3 & 20.0 \\
\hline Occas & 24 & 6.6 & 2 & 4.4 & 9 & 11.8 & 2 & 13.3 \\
\hline Freq & 19 & 5.2 & 1 & 2.2 & 9 & 11.8 & 1 & 6.7 \\
\hline Always & 24 & 6.6 & 6 & 13.3 & 4 & 5.3 & 4 & 26.7 \\
\hline Total & $\mathbf{3 6 3}$ & $\mathbf{1 0 0 . 0}$ & $\mathbf{4 5}$ & $\mathbf{1 0 0 . 0}$ & $\mathbf{7 6}$ & $\mathbf{1 0 0 . 0}$ & $\mathbf{1 5}$ & $\mathbf{1 0 0 . 0}$ \\
\hline
\end{tabular}

Regular Soda

\begin{tabular}{|c|c|c|c|c|c|c|c|c|}
\hline Age & \multicolumn{2}{|c|}{$\mathbf{1 8 - 2 4}$} & \multicolumn{2}{c|}{$\mathbf{2 5 - 3 0}$} & \multicolumn{2}{c|}{$\mathbf{3 1 - 5 0}$} & \multicolumn{2}{c|}{ Over 50 } \\
\hline & $\mathrm{n}=$ & $\%$ & $\mathrm{n}=$ & $\%$ & $\mathrm{n}=$ & $\%$ & $\mathrm{n}=$ & $\%$ \\
\hline NvrDrk & 121 & 33.3 & 12 & 26.7 & 27 & 35.5 & 8 & 53.3 \\
\hline Rarely & 60 & 16.5 & 4 & 8.9 & 15 & 19.7 & 1 & 6.7 \\
\hline Occas & 69 & 19.0 & 9 & 20.0 & 10 & 13.2 & 2 & 13.3 \\
\hline Freq & 72 & 19.8 & 12 & 26.7 & 12 & 15.8 & 2 & 13.3 \\
\hline Always & 41 & 11.3 & 8 & 17.8 & 12 & 15.8 & 2 & 13.3 \\
\hline Total & $\mathbf{3 6 3}$ & $\mathbf{1 0 0 . 0}$ & $\mathbf{4 5}$ & $\mathbf{1 0 0 . 0}$ & $\mathbf{7 6}$ & $\mathbf{1 0 0 . 0}$ & $\mathbf{1 5}$ & $\mathbf{1 0 0 . 0}$ \\
\hline
\end{tabular}

Satisfied with Physical Activity

\begin{tabular}{|c|c|c|c|c|c|c|c|c|}
\hline Age & \multicolumn{2}{|c|}{$\mathbf{1 8 - 2 4}$} & \multicolumn{2}{c|}{$\mathbf{2 5 - 3 0}$} & \multicolumn{2}{c|}{$\mathbf{3 1 - 5 0}$} & \multicolumn{2}{c|}{ Over 50 } \\
\hline & $\mathrm{n}=$ & $\%$ & $\mathrm{n}=$ & $\%$ & $\mathrm{n}=$ & $\%$ & $\mathrm{n}=$ & $\%$ \\
\hline Yes & 172 & 47.4 & 12 & 26.7 & 25 & 32.9 & 6 & 40.0 \\
\hline No & 191 & 52.6 & 33 & 73.3 & 51 & 67.1 & 9 & 60.0 \\
\hline Total & $\mathbf{3 6 3}$ & $\mathbf{1 0 0 . 0}$ & $\mathbf{4 5}$ & $\mathbf{1 0 0 . 0}$ & $\mathbf{7 6}$ & $\mathbf{1 0 0 . 0}$ & $\mathbf{1 5}$ & $\mathbf{1 0 0 . 0}$ \\
\hline
\end{tabular}

On a Diet to Lose Weight

\begin{tabular}{|c|c|c|c|c|c|c|c|c|}
\hline Age & \multicolumn{2}{|c|}{$\mathbf{1 8 - 2 4}$} & \multicolumn{2}{|c|}{$\mathbf{2 5 - 3 0}$} & \multicolumn{2}{c|}{$31-50$} & \multicolumn{2}{c|}{ Over 50 } \\
\hline & $\mathrm{n}=$ & $\%$ & $\mathrm{n}=$ & $\%$ & $\mathrm{n}=$ & $\%$ & $\mathrm{n}=$ & $\%$ \\
\hline Yes & 106 & 29.2 & 14 & 31.1 & 27 & 35.5 & 7 & 46.7 \\
\hline No & 257 & 70.8 & 31 & 68.9 & 49 & 64.5 & 8 & 53.3 \\
\hline Total & $\mathbf{3 6 3}$ & $\mathbf{1 0 0 . 0}$ & $\mathbf{4 5}$ & $\mathbf{1 0 0 . 0}$ & $\mathbf{7 6}$ & $\mathbf{1 0 0 . 0}$ & $\mathbf{1 5}$ & $\mathbf{1 0 0 . 0}$ \\
\hline
\end{tabular}

Fast Food Item-Hamburger

\begin{tabular}{|c|c|c|c|c|c|c|c|c|}
\hline Age & \multicolumn{2}{|c|}{$\mathbf{1 8 - 2 4}$} & \multicolumn{2}{|c|}{$\mathbf{2 5 - 3 0}$} & \multicolumn{2}{c|}{$\mathbf{3 1 - 5 0}$} & \multicolumn{2}{c|}{ Over 50 } \\
\hline & $\mathrm{n}=$ & $\%$ & $\mathrm{n}=$ & $\%$ & $\mathrm{n}=$ & $\%$ & $\mathrm{n}=$ & $\%$ \\
\hline Never & 52 & 14.3 & 5 & 11.1 & 11 & 14.5 & 1 & 6.7 \\
\hline Rarely & 73 & 20.1 & 3 & 6.7 & 13 & 17.1 & 3 & 20.0 \\
\hline Occas & 100 & 27.5 & 16 & 35.6 & 27 & 35.5 & 1 & 6.7 \\
\hline Freq & 117 & 32.2 & 17 & 37.8 & 19 & 25.0 & 8 & 53.3 \\
\hline Always & 21 & 5.8 & 4 & 8.9 & 6 & 7.9 & 2 & 13.3 \\
\hline Total & $\mathbf{3 6 3}$ & $\mathbf{1 0 0 . 0}$ & $\mathbf{4 5}$ & $\mathbf{1 0 0 . 0}$ & $\mathbf{7 6}$ & $\mathbf{1 0 0 . 0}$ & $\mathbf{1 5}$ & $\mathbf{1 0 0 . 0}$ \\
\hline
\end{tabular}

Fast Food Item-French Fries

\begin{tabular}{|c|c|c|c|c|c|c|c|c|}
\hline Age & \multicolumn{2}{|c|}{$\mathbf{1 8 - 2 4}$} & \multicolumn{2}{c|}{$\mathbf{2 5 - 3 0}$} & \multicolumn{2}{c|}{$31-50$} & \multicolumn{2}{c|}{ Over 50 } \\
\hline & $\mathrm{n}=$ & $\%$ & $\mathrm{n}=$ & $\%$ & $\mathrm{n}=$ & $\%$ & $\mathrm{n}=$ & $\%$ \\
\hline Never & 19 & 5.2 & 2 & 4.4 & 8 & 10.5 & 4 & 26.7 \\
\hline
\end{tabular}

\begin{tabular}{|c|c|c|c|c|c|c|c|c|}
\hline Rarely & 57 & 15.7 & 7 & 15.6 & 9 & 11.8 & 4 & 26.7 \\
\hline Occas & 90 & 24.8 & 10 & 22.2 & 20 & 26.3 & 4 & 26.7 \\
\hline Freq & 127 & 35.0 & 13 & 28.9 & 27 & 35.5 & 3 & 20.0 \\
\hline Always & 70 & 19.3 & 13 & 28.9 & 12 & 15.8 & & \\
\hline Total & $\mathbf{3 6 3}$ & $\mathbf{1 0 0 . 0}$ & $\mathbf{4 5}$ & $\mathbf{1 0 0 . 0}$ & $\mathbf{7 6}$ & $\mathbf{1 0 0 . 0}$ & $\mathbf{1 5}$ & $\mathbf{1 0 0 . 0}$ \\
\hline
\end{tabular}

Fast Food Item-Dessert

\begin{tabular}{|c|c|c|c|c|c|c|c|c|}
\hline Age & \multicolumn{2}{|c|}{$\mathbf{1 8 - 2 4}$} & \multicolumn{2}{|c|}{$\mathbf{2 5 - 3 0}$} & \multicolumn{2}{|c|}{$\mathbf{3 1 - 5 0}$} & \multicolumn{2}{c|}{ Over 50 } \\
\hline & $\mathrm{n}=$ & $\%$ & $\mathrm{n}=$ & $\%$ & $\mathrm{n}=$ & $\%$ & $\mathrm{n}=$ & $\%$ \\
\hline Never & 131 & 36.1 & 26 & 57.8 & 31 & 40.8 & 6 & 40.0 \\
\hline Rarely & 169 & 46.6 & 13 & 28.9 & 37 & 48.7 & 6 & 40.0 \\
\hline Occas & 50 & 13.8 & 5 & 11.1 & 6 & 7.9 & 3 & 20.0 \\
\hline Freq & 12 & 3.3 & 1 & 2.2 & 2 & 2.6 & 0 & 0 \\
\hline Always & 1 & .3 & 0 & 0 & 0 & 0 & 3 & 20.0 \\
\hline Total & $\mathbf{3 6 3}$ & $\mathbf{1 0 0 . 0}$ & $\mathbf{4 5}$ & $\mathbf{1 0 0 . 0}$ & $\mathbf{7 6}$ & $\mathbf{1 0 0 . 0}$ & $\mathbf{1 5}$ & $\mathbf{1 0 0 . 0}$ \\
\hline
\end{tabular}

Table 2: Results by Age Groupings, Demographics, and FF Survey items Population.

well as lifestyle and environmental factors is critical among college student and individuals of all ages.

Every sickness, disease, and ailment is the result of nutritional deficiency/s. Linus Pauling [15].

\section{References}

1. April JH, Jason LS, Xue Hua, Suh Lee, Derrek P. Hibar, et al. (2013) A commonly carried allele of the obesity-related FTO gene is associated with reduced brain volume in the healthy elderly. Proceedings from the National Academy of Sciences USA 107: 18.

2. Satcher D (2011) 'F' as in Fat: How obesity threatens America's furture 2011. Trust for Americans Health, Preventing epidemics, protecting people.

3. Services (2012) United States Department of Health and Human Services. Healthy People 2020.

4. Lovejoy JC (2013) Integrative approaches to obesity treatment. Integr Med A Clinic J 12: 30-35.

5. Life 123 (2012) History of the Food Guide Pyramid.

6. Willett WC (2001) Eat, Drink, and Be Healthy. New York, NY: Simon and Schuster.

7. University of Michigan Integrative Medicine (2012). Healing Foods Pyramid.

8. Ogden CL, Carroll MD (2010) Prevalence of Overweight, Obesity, and Extreme Obesity among Adults: United States Trends 1976-1980 through 2007-2008.

9. Sampey BP, Vanhoose AM, Winfield HM, Freemerman AJ, Muehlbauer MJ, et al. (2011) Cafeteria diet is a robust model of human metabolic syndrome with liver and adipose inflammation: Comparison to high-fat diet. Obesity 19: 1109-1117.

10. Snijder MB, van Dam RM, Visser M, Seidell JC (2006)What aspects of body fat are particularly hazardous and how do we measure them? Int $\mathrm{J}$ Epidemiol 35: 83-92.

11. Marsman HA, Heger M, Kloek JJ, Nienhuis SL, van Werven JR, et al. (2011) Reversal of hepatic steatosis by omega-3 fatty acids measured non-invasively by $\mathrm{H}$-magnetic resonance spectroscopy in a rat mode. $\mathrm{J}$ Gastroenterol Hepatol 26: 356-363.

12. Swenson A (2013) Jacob teitelbaum, M.D. Altern Med 32-37.

13. Hendricks J (2013) Inflammation: the trouble with chronic inflammation and what to do about it. Altern Med 51-53.

14. Insel PM, Roth WT (2012) Core Concepts in Health, 12th ed. New York: McGraw-Hill 324-367.

15. White SF (2013) The signs: Predicting genetic predisposition.

16. Pittas AG, Das SK, Hajduk CL, Golden J, Saltzman E, et al. (2005) A lowglycemic load diet facilitates greater weight loss in overweight adults with 
Citation: Stockton S, Baker DMA (2013) Obesity Etiology: Examination of Fast-Food Eating among College Students. Aging Sci 2: 114. doi: 10.4172/2329-8847.1000114

high insulin secretion but not in overweight adults with low insulin secretion in the CALERIE Trial.Diabetes Care 28: 2939-2941.

17. Fontana L, Eagon JC, Trujillo ME, Scherer PE, Klein S (2007) Visceral fat adipokine secretion is associated with systemic inflammation in obese humans. Diabetes 56: 1010-1013.

18. Rossi AP, Watson NL, Newman AB, Harris TB, Kritchevsky SB, et al. (2011) Effects of body composition and adipose tissue distribution on respiratory function in elderly men and women: The health, aging, and body composition study. J Gerontol A Biol Sci Med Sci 66A: 801-808.

19. Younossi ZM, Jarrar M, Nugent C, Randhawa M, Afendy M, et al. (2008) A novel diagnostic biomarker panel for obesity-related nonalcoholic steatohepatitis (NASH). Obes Surg 18: 1430-1437.

20. Dowman JK, Tomlinson JW, Newsome PN (2011) Systematic review: the diagnosis and staging of nonalcoholic fatty liver disease and nonalcoholic steatohepatitis. Aliment Pharmacol Ther 33: 525-540.

21. Kozlitina J, Boerwinkle E, Cohen JC, Hobbs HH (2011) Dissociation between APOC3 variants, hepatic triglyceride content, and insulin resistance. Hepatology 53: 464-474

22. Claesson MJ, Jeffrey IB, Conde S, et al. (2012) Altered gut microbiota associated with chronic conditions, obesity, inflammatory diseases, and aging. Nature 488: 178-184.

23. Partridge L (2012) Diet and healthy aging. New Engl J Med 367: 2550-2551.

24. Power BD, Almeida OP (2012) Obesity in later life and dementia risk: a tale of many paradoxes. Aging Health 8: 225-227.

25. de Souza RJ, Bray GA, Carey VJ, Hall KD, LeBoff MS, et al. (2012) Effects of 4 weight-loss diets differing in fat, protein, and carbohydrate on fat mass, lean mass, visceral adipose tissue, and hepatic fat: results from the POUNDS LOST trial. Am J Clin Nutr 95: 614-625.

26. Gardner CD, Kiazand A, Alhassan S, Kim S, Stafford RS, et al. (2007) Comparison of the Atkins, Zone, Ornish, and LEARN diets for change in weight and related risk factors among overweight premenopausal women: the A TO Z Weight Loss Study: a randomized trial. JAm Med Assoc 297: 969-977.

27. Yancy WS Jr, Olsen MK, Guyton JR, Bakst RP, Westman EC (2004) A low-carbohydrate, ketogenic diet versus a low-fat diet to treat obesity and hyperlipidemia: a randomized, controlled trial. Ann Intern Med 140: 769-77.

28. Sondike SB, Copperman N, Jacobson MS (2003) Effects of a low carbohydrate diet on weight loss and cardiovascular risk factor in overweight adolescents. J Pediatr 142: 253-8.
29. Hu T, Mills KT, Yao L, et al. (2012) Effects of low fat diets on metabloic risk factors: A meta-analysis of randomized controlled clinical trials. Am J Epidemiol 176:S44-S54.

30. Foster GD, Wyatt HR, Hill JO, Makris AP, Rosenbaum DL, et al. (2010) Weight and metabolic outcomes after 2 years on a low-carbohydrate versus low-fat diet: a randomized trial. Ann Intern Med 153:147-157.

31. Creely SJ, McTernan PG, Kusminski CM, Fisher fM, Da Silva NF, et al (2007) Lipopolysaccharide activates an innate immune system response in human adipose tissue in obesity and type 2 diabetes. Am $\mathrm{J}$ Physiol Endocrinol Metab 292: E470-477.

32. Marcos A, Nova E, Montero A (2003) Changes in the immune system are conditioned by nutrition. Eur J Clin Nutr 57 Suppl 1:S66-9.

33. Haines C, O'Neil C, Zanovec M (2010) Fast-food consumption among college students and their attitudes toward healthier fast-food options. Fed Am Soc Experi Biol J.

34. Barnes, Seraphine Pitt, Brown, Kelli McCormack, McDermott, et al. (2012) Perceived parenting style and the eating practices of college freshman. Am $J$ Health Ed 43: 8-17.

35. National health and nutrition examination survey (2013) Center for Disease Control and Prevention.

36. SurveyMonkey® (2012) Plans and Pricing.

37. Coronary Artery Risk Development in Young Adults (2010) CARDIA Study.

38. Swithers SE, Davidson TL (2008) A role for sweet taste: Calorie predictive relations in energy regulation by rats. Behav Neurosci 122: 161-173.

39. Stanton J (2012) The lipid hypothesis has officially failed.

40. Rosenblum JL, Castro VM, Moore CE, Kaplan LM (2012) Calcium and vitamin D supplementation is associated with decreased abdominal viscera adipose tissue in overweight and obese adults. Am J Clin Nutr 95: 101-108.

41. Maersk M, Belza A, Stødkilde-Jørgensen $H$, Ringgaard S, Chabanova E, et al. (2012) Sucrose-sweetened beverages increase fat storage in the liver, muscle, and visceral fat depot: a 6-mo randomized intervention study. Am J Clin Nutr 95: 283-289.

42. Niemeier BS, Hektner JM (2012) Weight-related health behaviors and body mass: associations between young adults and their parents, moderated by parental authority. Am J Health Ed 43: 366-381.

43. Multiple Chronic conditions: a strategic framework (2013) Department of Health and Human Services. 